\title{
Numerical investigation of flow through inclined fins under the absorber plate of solar air heater
}

\begin{abstract}
The world today is going through a phase of uncertainty in terms of provision of power and energy because of shortages of fossil fuels, and these issues are increasing the costs as well as developing uncertain economic conditions worldwide. Hence, there is a dire necessity to find a solution to this problem by finding sustainable alternative power and energy solutions. However, the thermal performance of the conventional SAH is found to be poor due to low convective heat transfer coefficient between the heat collecting surface and working fluid. Therefore, increasing the convection heat transfer coefficient is essential so that thermal system performance can also be increased. In the present research, a numerical evaluation was carried out on the heat transfer and the flow friction processes in a SAH coupled with inclined fins underneath the absorber plate. With a constant heat flux application $(1000 \mathrm{~W} / \mathrm{m} 2)$, the average Nusselt number $(\mathrm{Nu})$ and friction factor, as well as the thermo-hydraulic performance parameter (THPP), were comprehensively investigated. The research covered different slant angle $(\alpha)$ of fins in the range of $30^{\circ}-75^{\circ}$, different pitch $(\mathrm{P})$ of fin in the range of $15-25 \mathrm{~mm}$ and a range of 4000-24000 for the Reynolds numbers (Re). For the current CFD evaluation, ANSYS FLUENT (v16.1) with renormalization group turbulence model is selected for computational domain analysis. In general, a significant improvement of the heat transfer in a SAH having inclined fins has been achieved. Moreover, with a view to analyzing the total effect of the slant angle and pitch of fin, the THPP subjected to similar pumping power constraint was calculated. From the investigated range, a maximum THPP of 1.916 was achieved by utilizing fins with $\alpha=45^{\circ}$ and $\mathrm{P}=20 \mathrm{~mm}$ at $\mathrm{Re}=20,000$. Finally, the proposed inclined fin's THPP was compared to other geometries such as, L-shaped (THPP $=1.90$ ), square $(\mathrm{THPP}=1.80)$, and circle $(\mathrm{THPP}=1.65)$. As a result, a better THPP of 1.916 was observed for this study.
\end{abstract}

Keyword: CFD; Solar air heater; Inclined fins; THPP 